\title{
REVIEW \\ Development of a Drip Fertigation System for Protected Horticulture on Sloping Land
}

\author{
Hiroki KAWASHIMA* \\ NARO Western Region Agricultural Research Center (WARC) (Zentsuji, Kagawa 765-0053, Japan)
}

\begin{abstract}
A drip fertigation system was developed to improve vegetable production in sloping greenhouses. The system comprised a control unit, fertilizer injection unit, feed tank, feed pump, feed valves, and nutrient reservoir, which are also used in flatland drip fertigation systems. These components were placed in the upper part of a sloping greenhouse, and dripper lines with diaphragms were installed on longitudinal ridges. However, it resulted in unbalanced irrigation along the slope because when the irrigation was complete, the nutrient solution and water remaining in the dripper lines flowed out of drippers in the lower part of the dripper lines due to gravity. This problem was solved using a newly developed system, featuring a drainpipe and drain valve installed at the lower end of the dripper lines. On completing fertigation, the drain valve, which had been closed during the irrigation, was opened. The nutrient solution and remaining water in the dripper lines then immediately flowed into the drainage reservoir via gravity and not onto the field.
\end{abstract}

Discipline: Horticulture

Additional key words: drain valve, dripper line, nutrient solution, unbalanced irrigation

\section{Introduction}

Sloping-land agriculture comprises one-third of the total farming area in Japan. Japanese agriculture faces a number of serious problems, including depopulation, aging farmers, and increasing abandonment of farmland ${ }^{10,13}$. These problems are also rapidly intensifying, particularly in sloping-land agriculture. Small-scale sloping fields result in inefficient farming and hinder mechanization. Such fields also delay the building of farm roads, hindering access to the field for machinery and farm workers ${ }^{13}$. This situation resembles that of agriculture in developing countries, particularly those with rapidly growing economies. In contrast, sloping-land agriculture offers potential due to its more versatile characteristics compared with those of flatland agriculture. Namely, the local resources and natural variation in the conditions of sloping land, including intricate topography and differing temperatures in the same region due to altitude, will enable the production of high quality or high value-added crops $^{13}$. Further, new trends are found in these areas, such as the establishment of horticultural centers and opening of new markets ${ }^{10}$. Masubuchi ${ }^{10}$ also pointed out the importance of using agricultural facilities, or greenhouses, and small machines on the sloping land. Facilities and labor-saving technologies used to establish new production systems for sloping-land horticulture have been developed, and include sloping greenhouses, which utilize sloping land effectively, and a portable monorail-type sprayer ${ }^{12}$.

Fertigation is a method of feeding nutrient solutions and water to crops effectively by adding soluble fertilizers to an irrigation system, saving time and labor and ensuring uniform water distribution ${ }^{15}$. Fertigation can feed nutrient solution and/or water automatically by programmed schedules. Bar-Yosef ${ }^{10}$ reported that the agricultural area on which micro-irrigation or drip fertigation is used is expanding almost linearly, particularly in the Far East (China, India, and Japan) and Australia. However, the use of drip fertigation is negligible in developing countries. The drip fertigation system was introduced to many flatland vegetable and/or flower growers in Japan because of its benefits, which include reduced labor for fertilization (or irrigation), decreased irrigation and fertilizer, and reduced cost of fertilizer ${ }^{1,2}$. The drip fertiga-

*Corresponding author: e-mail hirokik@affrc.go.jp

Received 1 February 2012; accepted 27 July 2012. 
tion system is also available for vegetable and flower production $^{2,4,9,15}$. This system will also be usable for sloping-land horticulture. However, the drip fertigation system used on flatland has certain problems when applied to crop production on sloping land, resulting in unbalanced fertigation along the slope. There have been a few investigations regarding the designs and methods of drip fertigation (or irrigation) on sloping land ${ }^{11}$. Morinaga et al. ${ }^{11}$ developed a drip fertigation system for satsuma mandarin (Citrus unshiu), which was cultivated on a bench terrace across the slope. Protected horticulture in a sloping greenhouse is not on a large scale and needs precise fertigation (or irrigation). Accordingly, we developed a drip fertigation method that was applicable to the drip fertigation system used in sloping greenhouses in protected agriculture.

\section{Outline of the developed drip fertigation system}

The standard drip fertigation system consists of a control unit, feed tank (water resource), feed pump, nutrient reservoir, fertilizer injection unit with a pressure reducing valve, and feed valves installed at the upper end of the dripper lines, which are, in turn, installed on longitudinal ridges in a sloping greenhouse (Fig. 1). In the newly developed system, a drainpipe, drain valve, drainage reservoir, and circulating pump, which were installed at the lower end of the dripper lines, were added to this existing system.

The operation of the developed drip fertigation system is described below. First, fertigation was conducted using pre-programmed fertigation schedules. Upon completion of the fertigation, the drain valve, which had been closed during the fertigation, was opened, whereupon the

a) In the case of longitudinal ridges

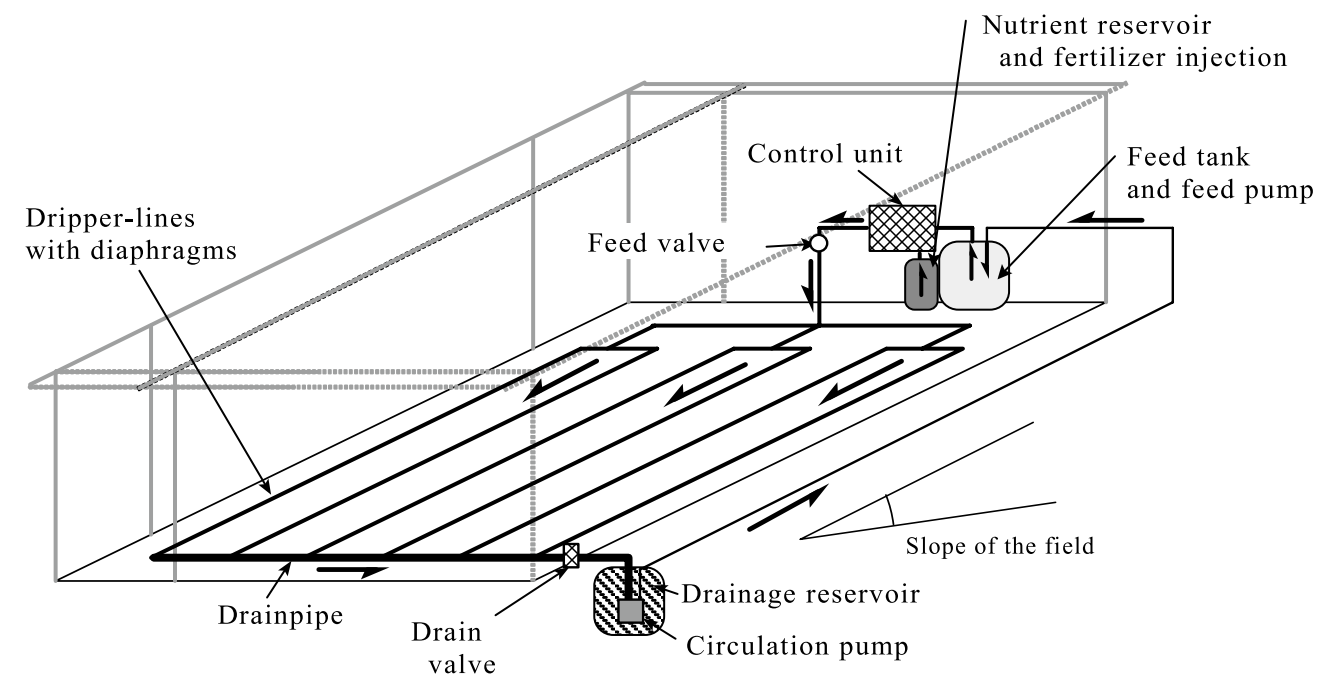

b) In the case of contour ridges

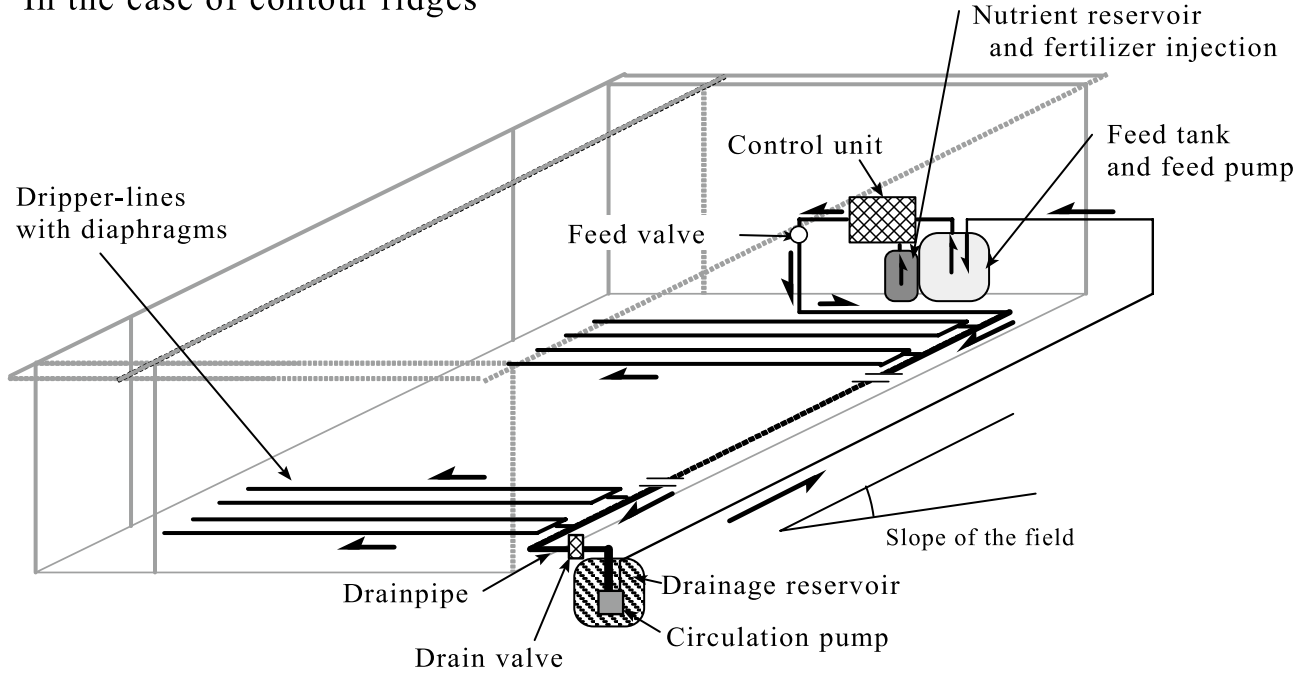

Fig. 1. Outline of a drip fertigation system in a flat-roof sloping greenhouse 
nutrient solution and/or remaining water in the dripper lines then immediately flowed into the drainage reservoir by gravity. Before opening the drain valve, the remaining nutrient solution in the dripper lines was replaced with water to change the mode from nutrient solution feeding to irrigation. The drained water containing no nutrients could be recycled as feed water, and was accordingly pumped to the feed tank.

\section{Development of drip fertigation in a sloping greenhouse}

The drip fertigation system described above was installed in a sloping greenhouse, which was constructed on a field sloping at a mean incline of approximately 10 degrees. Two dripper lines, $27 \mathrm{~m}$ in length, were installed on each of the 3 ridges in the sloping greenhouse and connected to the drainpipe at the lower end. A drain valve was installed at the end of the drainpipe.

Drippers of the dripper line (Ram 17; NETAFIM, Israel) were spaced $0.3 \mathrm{~m}$ apart, and in each, a pressurecompensating device (diaphragm) was installed. There are several types of drippers or emitters ${ }^{3,6}$. The dripper line used here contained a pressure-compensating device, which was assumed to maintain high emission uniformity, even on sloping land (Fig. 2). The application of this system depends on the performance of the dripper lines, while the pressure compensation requires an available range in the pressure head ${ }^{6,11}$. The pressure at the end of the dripper line caused by elevation must be within

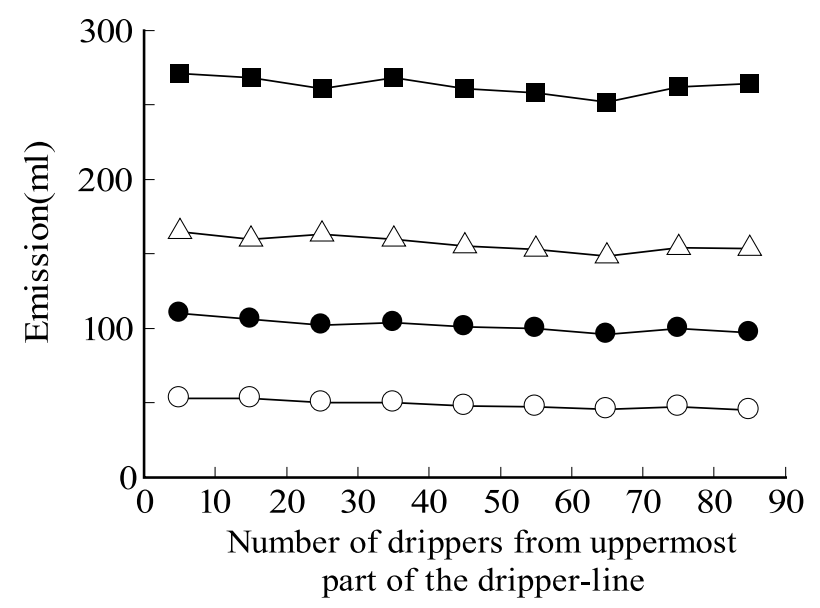

Fig. 2. Emission from drippers in a dripper line along the slope

Total amount of water fed into the dripper lines: $\bigcirc$, $20 \mathrm{~L} ; 0,30 \mathrm{~L} ; \triangle, 40 \mathrm{~L} ; \mathbf{\square}, 60 \mathrm{~L}$. Drippers were spaced at $0.3-\mathrm{m}$ intervals. Measurements were taken from 2 dripper lines in the sloping greenhouse with a mean slope of approximately 10 degrees. The emission from each dripper was measured. this range when the dripper lines are installed on longitudinal ridges. Although there was no difference in emission from each dripper during fertigation, emission levels from drippers varied when irrigation was conducted using the standard method practiced on flatland.

Emissions from the dripper at the lower part of the dripper line were highest, followed by that at the middle and upper parts of the dripper line when the irrigation was conducted using standard methods (Fig. 3). Namely, upon completion of the fertigation, the remaining nutrient solution in the dripper lines flowed from the drippers onto the field at the lower part of the dripper line due to gravity (Table 1). Higashide et al..$^{5}$ also showed that a considerable amount of solution leaked from the lowest line after finishing the fertigation when the dripper lines were set at contours. When fertigation was conducted with the developed system, emissions from the dripper were uniform and no emission was found upon completion of fertigation. Since the developed drip fertigation system achieved uniform growth of vegetables and flowers ${ }^{8}$, it appears suitable for vegetable and flower cultivation in sloping greenhouses.

Higashide et al. ${ }^{5}$ used dripper lines providing drainage that shut off below a certain pressure, into which check valves were inserted to stop drainage from the lowest line. However, the above-described system was also usable with the dripper (lateral) lines set at contours (Fig. 4). In this case, the main pipe was set at a longitudinal line in the sloping greenhouse and the drain valve was installed at the lowest end of the main pipe in a longitudinal line on the slope (Fig. 1b).

An increasing number of farmers are adopting the drip fertigation system, although growth remains modest. One of the reasons is the high initial cost associated with

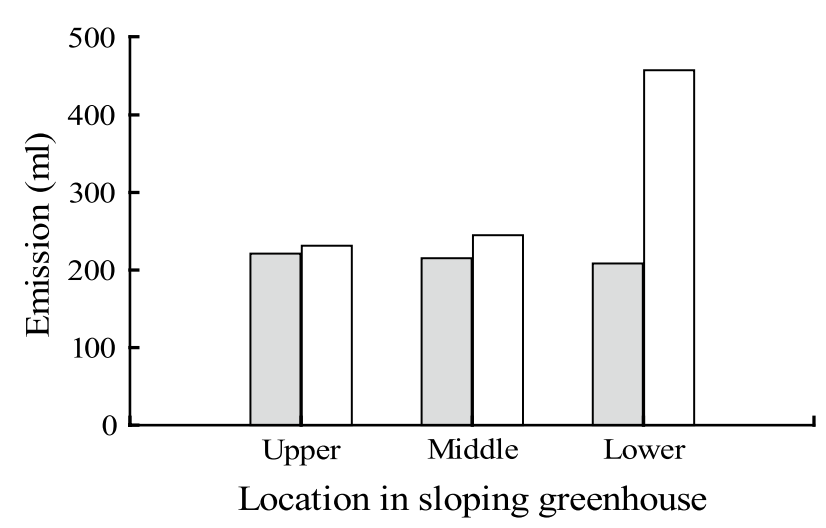

Fig. 3. Effect of the irrigation method on emissions from drippers in a dripper line along the slope

$\square$, Improved method; $\square$, Standard method. Measurements were conducted in a sloping greenhouse with a mean slope of approximately 10 degrees. The emission from each dripper was measured. 
Table 1. Effect of irrigation method on the emission time of water remaining in the dripper line at the end of the irrigation

\begin{tabular}{lccc}
\hline \hline Method & Upper & Middle & Lower \\
\hline Standard & 15 & 85 & 1200 \\
Improved & 0 & 0 & 0 \\
\hline
\end{tabular}

Values are the time (sec) from the end of the irrigation to the end of the emission from the dripper. Measurements were conducted in a sloping greenhouse with a mean slope of approximately 10 degrees. The emission from each dripper was measured.

drip fertigation. Small-scale farmers, particularly in sloping-land agricultural areas, lack funding to introduce new facilities into their greenhouses ${ }^{1}$, which will hamper efforts to apply this system in developing countries. One of the major problems is the quality of the water, which clogs the drip fertigation system with physical contaminants, hence filtering devices are crucial. A lack of electricity is also anticipated, while some low-cost systems are also under-developed ${ }^{7,14}$. One example is the automated pulsating drip fertigation system that operates via a solar pump and is used for horticultural production in open fields ${ }^{16}$. Adapting the components of this system to the drip fertigation system developed for sloping greenhouses is expected to be one of the factors enabling its introduction.

\section{References}

1. Asami, I. \& O. Tsuji (2003) Degree of satisfaction and results of introduction for the management of the protected vegetative farmhouses adopted drip-fertigation system. Res. Bull. Aichi Agric. Res. Ctr., 36, 115-122 [In Japanese with English summary].

2. Bar-Yosef, B. (1999) Advances in fertigation. Adv. Agron., 65, 1-77.

3. Goto, H. et al. (2002) The hydraulic characteristics of drip tubes used for drip-fertigation and the effect of emitter spacing of the drip tube upon the growth and yield of tomatoes. Res. Bull. Aichi Agric. Res. Ctr., 34, 67-72 [In Japanese with English summary].

4. Hochmuth, G. J. et al. (1996) Nitrogen fertigation requirements of drip-irrigated strawberries. J. Amer. Soc. Hort. Sci., 121, 660-665.

5. Higashide, T. et al. (2005) Development of a closed, costand energy-saving hydroponic system for hillside tomato production. Hort. Res. (Japan), 4, 33-40 [In Japanese with English summary].

6. Karmeli, D. (1977) Classification and flow regime analysis of drippers. J. Agric. Eng. Res., 22, 165-173.

7. Kawai, J. et al. (2003) Development of flow control device

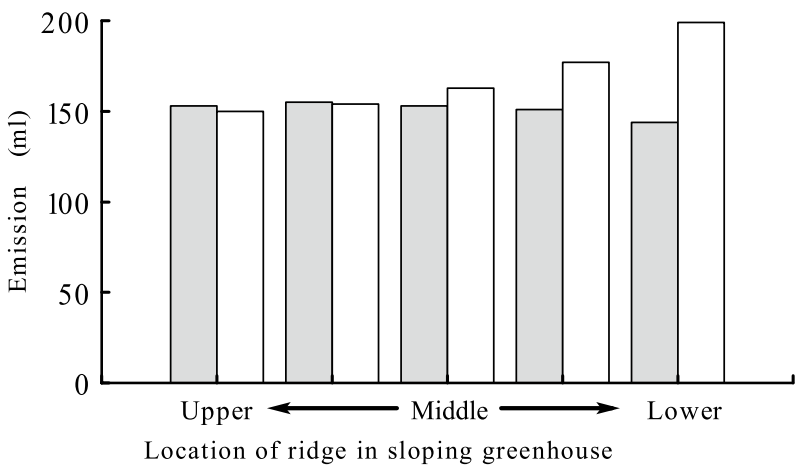

Fig. 4. Effect of the irrigation method on emissions from drippers in dripper lines set at contours

$\square$, Improved method; $\square$, Standard method. Measurements were conducted in a sloping greenhouse with a mean slope of approximately 10 degrees. The emission from each dripper was measured.

for drip-fertigation that incorporated the flow meter that transmits the pulse. Res. Bull. Aichi Agric. Res. Ctr., 35, 109-114 [In Japanese with English summary].

8. Kawashima, H. et al. (2000) The drip fertigation system for vegetable cultivation in sloping greenhouses. Proc. Intl. Agric. Eng. Conf., 272-276.

9. Locacui, S. J. et al. (1997) Nitrogen and potassium application scheduling effects on drip-irrigated tomato yield and leaf tissue analysis. HortScience, 32, 230-235.

10. Masubuchi, R. (1997) Regional characteristics and reorganization of agriculture in hilly and mountainous areas. Bull. Shikoku Natl. Agric. Exp. Stn., 61, 135-147 [In Japanese with English summary].

11. Morinaga, K. et al. (2004) Novel system for high quality and stable production of Satsuma mandarin using a drip irrigation and liquid fertigation system with year-round plastic mulching. Hort. Res. (Japan), 3, 45-49 [In Japanese with English summary].

12. Nagasaki, Y. et al. (2005) Studies on machinery and facilities for various vegetable production. Bull. Natl. Agric. Res. Cent. Wes. Reg., 4, 129-171 [In Japanese with English summary].

13. Nakagawa, S. (1997) The current situation and future tasks in slopeland agriculture in Japan and Asia. Study Meeting on Sustainable Farming Systems in Upland Areas-Resource Papers Session in Takamatsu, 1-17.

14. Nitta, M. et al. (2009) Development of an irrigation control device based on solar radiation and its adaptability for cultivation of high soluble solid tomato fruit in root zone restriction culture. Bull. Kochi Agric. Res. Cent., 18, 31-38 [In Japanese with English summary].

15. Scanders, D. C. (1996) Drip fertigation systems. Far East Agriculture. Nov/Dec, 17-20.

16. Yoshikawa-Yamanishi, H. \& S. Nakao (2010) Construction procedure of the automated pulsating drip-irrigation system using solar pump. Misc. Pub. Natl. Agric. Res. Cent. West Reg., 7, 21-31. 